\title{
Evaluation of Children's Lunch Box Contents by Photograph and Their Relationship with Mothers' Concern
}

\author{
Tomoko Osera $^{1,2}$, Setsuko Tsutie ${ }^{3}$, Misako Kobayashi $^{2} \&$ Nobutaka Kurihara $^{1}$ \\ ${ }^{1}$ Hygiene and Preventive Medicine, Graduate School of Life Science, Kobe Women's University, Japan \\ ${ }^{2}$ Takakuradai Kindergarten attached to Kobe Women's University, Japan \\ ${ }^{3}$ Clinical Nutrition Management, Graduate School of Life Science, Kobe Women's University, Japan \\ Correspondence: Nobutaka Kurihara, Graduate School of Life Science, Kobe Women's University, 2-1 \\ Higashisuma-Aoyama, Suma, Kobe, Japan. Tel: 81-78-737-2417. E-mail: kurihara@ suma.kobe-wu.ac.jp
}

Received: October 20, 2016

Accepted: December 18, 2016 Online Published: January 7, 2017

doi:10.5539/jfr.v6n1p78

URL: http://dx.doi.org/10.5539/jfr.v6n1p78

\begin{abstract}
Japanese kindergarten children usually bring lunch prepared by mothers. The contents may be influenced by mothers' food concerns. We investigated the relationship between mothers' concerns and children's lunch box contents and preferences. Lunch boxes of 209 children were digitally photographed for 4 days at a private kindergarten in Japan. The amounts of rice, main dishes, vegetables and fruits in the lunch boxes were estimated by measuring the area occupied by each in the photograph; a questionnaire, including questions on mothers' concerns and children's preferences, was completed by mothers. Vegetable amounts in the lunch boxes were significantly related to mother's concerns for their children's lunch. Compared with estimated vegetable amounts below $11 \%$, the amounts above $11 \%$ indicated that the number of foods disliked by children was lower, and mothers reported a higher rate of mindfulness towards vegetables and lower rate towards frozen food and believed that they prepared a balanced lunch. Thus, vegetable amounts in children's lunch boxes, estimated using photographs, may predict mothers' food concerns and children's balanced/unbalanced diets.
\end{abstract}

Keywords: Children's Lunch Box, Photograph, Vegetables, Mothers’ concern

\section{Introduction}

Mothers' attitude toward children acquiring healthy food habits may have an influence on children's consumption. The aim of this study is to investigate the relationship between mothers' concerm for lunch box and children's lunch box contents. In the study, we investigate to mother's concern for children pay attention to their lunch box. In Japan, children at nursery facilities usually eat school lunches, while those at kindergartens usually bring packed lunches from home. There are no standards for ensuring that children bring healthy packed lunches in the UK (Rees, Richards \& Gregory, 2008, Evans et al., 2010a) where approximately half of the school pupils get packed lunch from home (Smithers et al., 2000) similar trends have been observed in Japan, and it seems that foods cooked by mothers are included in children's packed lunches.

Mothers must be careful regarding the contents of the packed lunches. However, one study (Rees, Richards \& Gregory, 2008) reported that in the UK, very few packed lunches contained vegetables, and fruit intake was particularly low for those having a school meal. Moreover, Evans et al. (2010a) reported that few packed lunches met the school meal standards. In the US, $41 \%$ of the elementary school children brought lunch to school on any given day, of which $45 \%$ brought snacks (Hubbard et al., 2013). In Australia, almost all children had some form of 'junk food' in their packed lunches, with a mean of $3.1 \pm 0.1$ servings (Sanigorski et al., 2005). This indicates that children's packed lunch contains few vegetables in these countries. Similarly, the packed lunches of Japanese children may also contain unbalanced diets, although little research has been conducted on this subject in the kindergarten children. Thus, the contents may be influenced by the mothers' food concern. In this study, we investigated the varieties of foods contained in the children's packed lunches by mothers' with various food concerns.

Early childhood is the most important period for establishing healthy eating habits and controlling children's preferences. Childhood is a sensitive period for development of food acceptance patterns (Nicklas et al., 2001, Ilingworth \& Lister, 1964, Cashidan, 1994). Likes and dislikes are easily acquired during the early years of life 
(Birch, 1979, Birch \& Fisher, 1998); Vereeken and Maes (2010) reported that young children's dietary habits were associated with the mothers' nutritional knowledge and attitudes. Thus, the mother's role is important in establishing a child's eating habits and preferences. In this study, we compared the frequency of eating a school lunch with that of eating a packed lunch. We investigated the relationship between the frequency of bringing a packed lunch to the school, mothers' concerns for the foods in lunches packed by them and children's preferences.

It has been well established that the foods consumed, particularly vegetables, are very important for overall health. Consumption of vegetables prevents conditions, such as cardiovascular diseases, stroke, hypertension, diabetes, obesity, and certain types of cancer, leading to enhanced human longevity (Zhang et al., 2011, Apped et al., 1997, World Cancer Research Fund \& American Institute for Cancer Research, 2007, Carter et al., 2010). Food intake in individuals is influenced by many factors, such as age, sex, eating habits, knowledge of nutrition, individual preferences, overall health and social status (Osera et al., 2016a, MacFarlane, Crawford \& Worsley, 2010, Bauer et al., 2008, Hlimi et al., 2012). Among these, preferences are one of the primary determinants of food intake (Cook, Wardle \& Gibson. 2003, Dovey et al., 2008). We hypothesized that the contents of children's packed lunch reflect mothers' concerns for children's diet.

In order to test this hypothesis, we conducted an investigation in Japan to determine the percentage of space in children's lunch box accounted for by the vegetables and the effect of food preference as well as the mothers' concerns on this percentage. In addition, the relationship between mothers' concerns and contents of children's lunch boxes was assessed.

\section{Method}

\subsection{Participant (Subject) Characteristics}

We photographed children's lunch boxes that were assigned an ID number using a digital camera on three occasions over the course of a school year at a private kindergarten in Hyogo Prefecture, Japan, from April 2013 to March 2014. Using photographs, we classified the contents of each packed lunch into five groups: 1) rice (e.g., staple foods with grains), 2) main dishes (e.g., meat, poultry, eggs and fish), 3) vegetables, 4) fruits and 5) sweets (e.g., jelly or Jell-O) (Figure 1). We also measured the percentage of space accounted for by each food group in 209 lunch boxes. The amount of food from each group was then estimated in the lunch boxes of 209 children by measuring the area in the photograph with an image-analysing program. We performed the estimations by measuring the area in the photograph using Image $\mathbf{J}$, and calculated the average of the three occasions for each food group.

The mothers were adequately informed about the objectives and methods of this investigation, and they answered the questionnaire voluntarily, with the right to withdraw at any time during the study. Individual privacy was strictly protected throughout the investigation. Under these conditions, the mothers agreed to cooperate with the scientific investigation while their children were included in this study. The study was performed after receiving approval from the principals of the kindergarten and nursery facilities. The study was also approved by the president of the kindergarten and the Kobe Women's University people's ethics committee.
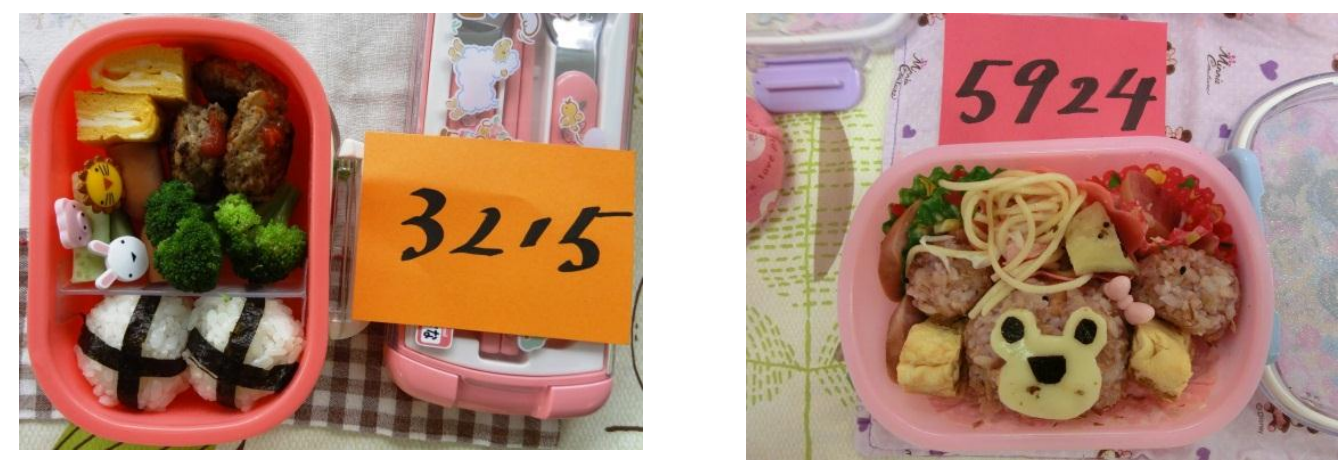

Figure 1. Children's packed lunch with ID number 


\subsection{Research Design}

Data were analysed together with a questionnaire regarding mothers' concerns for children's lunch boxes and their eating habits at the end of the investigation. In March 2014, questionnaires were distributed to mothers of the children who attended a private kindergarten in Hyogo Prefecture, Japan. The questionnaire sheets were distributed to the mother of each child (i.e., a mother with two children in kindergarten received two sheets and answered the questions regarding each child). In total, questionnaires from $264(79 \%)$ children were collected; of them, 209 were included in the study. Mothers of 209 corrected all study that submitted questionnaire and their children bring packed lunch all day.

\subsection{Questionnaire}

The questionnaire completed by the mothers included 50 questions and had three sections: 1) children's food habits (18 questions), 2) mothers' food habits (14 questions) and mothers' concerns for their children's lunch box contents (18 questions). We defined the mother's concern for her child's lunch box as 'preparation time', 'consideration of the nutritional balance for the child's packed lunch' and 'the frequency of using frozen food'. We were obvious this questionnaire's reliability. This questionnaire is a revised version of the one originally created by the Japan Sports Council that was used to determine the food habits of elementary school children and junior high school students (Japan Sports Council, 2010). We revised it to specifically determine the food habits of children aged between 3 and 5 years and their guardians. These improvisations proved to be adequate, and we checked the reliability of the revised version. Specifically, questions regarding mothers' concerns for children's packed lunches were added to the original version. For the calculated data presented in Table 1, the median percentage of vegetables was $11 \%$. Banalization of data was performed to divide it into two groups as shown in Table 2 and Figure 2.

a)

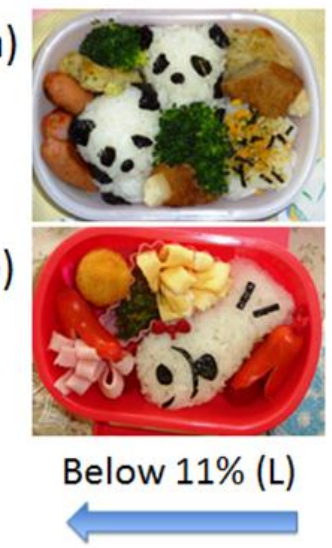

c)

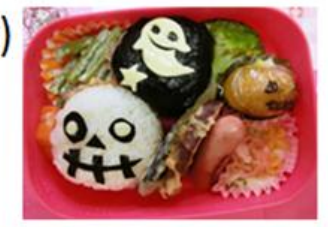

d)

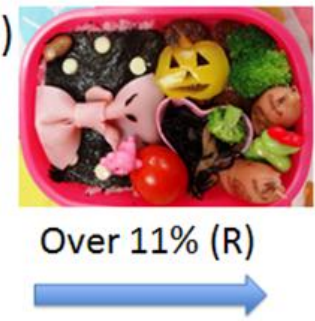

Figure 2. Examples of children's packed lunches estimated vegetable amounts

Photographs on the left side show packed lunches with vegetable amounts below $11 \%$; a) and b).

Those on the right side show packed lunches with vegetable over 11\%; c) and d).

\subsection{Statistics and Data Analysis}

We used a five-point or a four-point rating scale in our research, with the highest point indicating good food habits. The foods that the children disliked were chosen from a list of 55 foods selected from those available at regular school lunches and often disliked by children as shown in our previous study (Osera et al., 2012). SPSS version $21.0 \mathrm{~J}$ was used for all statistical analyses. In addition, all data were analysed using a Fisher's exact test and Mann-Whitney U test. Study consisted of only the questionnaire; we attempted to determine a relation between the contents of the lunch box and the answers to the questionnaire regarding food habits. Children's lunch box and questionnaire had the same ID (Figure 1).

\section{Results}

Using photographs, the contents of each lunchbox were classified into five groups: 1) rice, 2) main dishes, 3) various kinds of vegetables, 4) fruits and 5) sweets. The percentages of area for each of the five groups were $37.9 \% \pm 9.2 \%, 37.3 \% \pm 10.0 \%, 11.9 \% \pm 7.8 \%, 8.9 \% \pm 7.9 \%$ and $2.0 \% \pm 3.7 \%$, respectively (Table 1, Figure 3). The areas for vegetables, including broccoli and tomato, were combined and presented as a single area. 
Table 1. Estimated amount of each group in lunch boxes

\begin{tabular}{crllcc}
\hline & Mean & \pm & SD & Max & Min \\
\hline Rice & 37.9 & \pm & 9.2 & 63 & 9 \\
Main dishes & 37.3 & \pm & 10 & 62 & 6 \\
Vegetables & 11.9 & \pm & 7.8 & 38 & 0 \\
Fruit & 8.9 & \pm & 7.9 & 32 & 0 \\
Sweets & 2.0 & \pm & 3.7 & 17 & 0 \\
\hline
\end{tabular}

Note. $\mathrm{N}=209$

A total of three packed lunches per person.

Average of 209 children's lunch boxes.

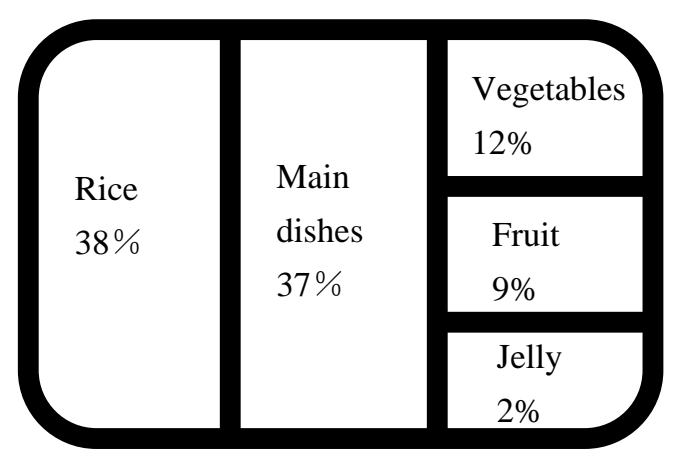

Figure 3. Average of children's lunch box contents

For the calculated data presented in Table 1, the median percentage of vegetables was $11 \%$. Banalization of data was performed to divide it into two groups as shown in Table 2 and Figure 2. The number of foods disliked by children was smaller when the percentage of the 'vegetables' area was above $11 \%(p<0.01$, Table 2$)$. A greater percentage of the guardians associated with this area were mindful of vegetables, while only a small percentage used frozen food ( $p<0.01$, each). In cases with the percentage of the 'vegetables' area below $11 \%$, these results were even lower. Therefore, the percentages of 'vegetables' area above or below $11 \%$ were significantly related with mothers' consideration of a balanced lunch box $(\mathrm{p}<0.01)$. In addition, watching TV and school lunch fun was significantly related to the 'vegetables' area $(\mathrm{p}<0.05$, each). Thus, the percentage of 'vegetables' area may be related to children's unbalanced or balanced diets and mothers' concern for food.

Table 2. Relationship between the side dish area, children's food habits and mothers' concerns for the children's packed lunch

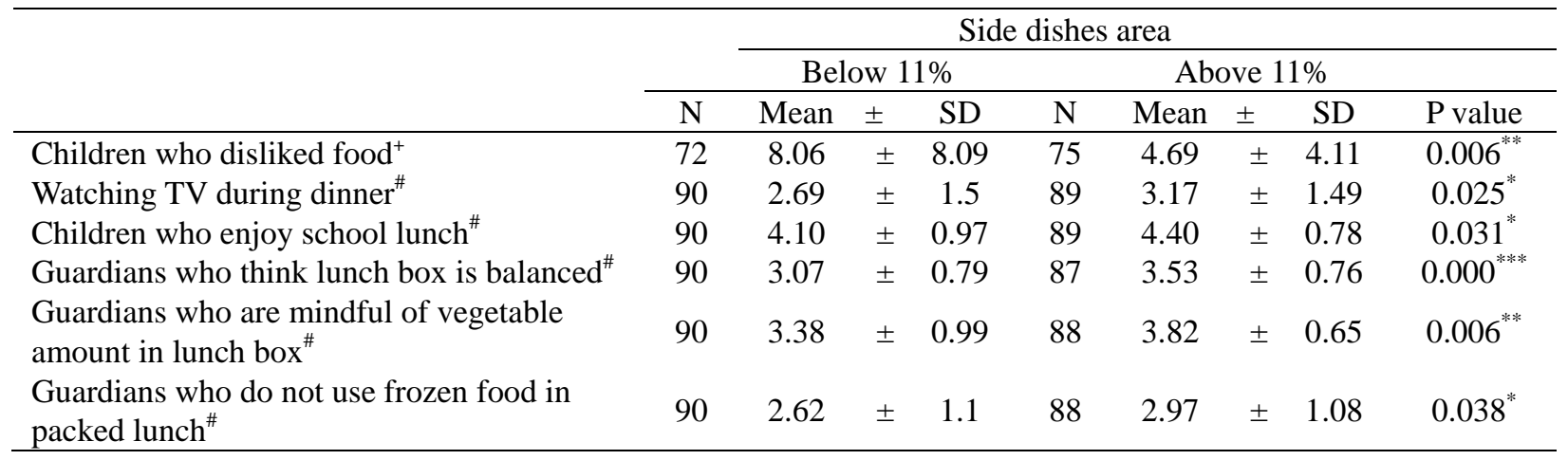

Note. When we calculated the data from Table 1, the percentage of the median values of vegetables was $11 \%$. Banalization is the process of dividing the data into two groups presented above.

The amount of the 'vegetables' area below $11 \%$ vs. above $11 \%$ was assessed for significance using a Mann-Whitney U test.

${ }^{*} \mathrm{p}<0.05,{ }^{* *} \mathrm{p}<0.01,{ }^{* * *} \mathrm{p}<0.001$

This binary distinction was performed according to the median value.

+ Guardians selected the children's disliked foods from 55 food items.

\# A five-point scale; the highest point indicates good habits. 
A total of $52.9 \%$ of the children had a lunch box that contained some vegetables. We investigated whether tomatoes and other types of vegetables were present in their lunch box (Table 3). We found that $49.5 \%$ of the lunch boxes contained at least one tomato. Therefore, the percentage of 'vegetables' area or the presence of tomatoes in children's lunch box was related to their well-balanced diets and mothers' concerns for food.

'Guardians who think that packed lunch is well-balance' was related to the number of different types of vegetables in lunch boxes. Moreover, we found a relationship between the number of different types of vegetables or the presence of tomatoes and 'nutritional balance' ( $p<0.01$ for both; Table 4$)$. In addition, there was a relationship between the presence of tomatoes, 'nutritional balance' and 'the time taken by mothers to prepare the packed lunch' (Table 5). Furthermore, the presence of tomatoes in the lunch box was determined to be related to children's balanced diets and mothers' concerns for food.

Table 3. Relationship between the types of vegetables and presence of tomatoes

\begin{tabular}{cccccc}
\hline & \multicolumn{4}{c}{ Tomato } \\
\hline & \multicolumn{4}{c}{ Presence } & \multicolumn{2}{c}{ Absence } \\
\hline The types of & 1 & 11 & $(27.5)$ & 29 & $(72.5)$ \\
vegetables & 2 & 22 & $(56.4)$ & 17 & $(43.6)$ \\
in the lunch box & 3 & 14 & $(63.6)$ & 8 & $(36.4)$ \\
& 4 & 6 & $(75.0)$ & 2 & $(25.0)$ \\
& 5 & 1 & $(100)$ & 0 & $(0)$ \\
& 6 & 1 & $(100)$ & 0 & $(0)$ \\
& All & 55 & $(49.5)$ & 56 & $(50.5)$ \\
\hline
\end{tabular}

Note. $\mathrm{N}=111$

We randomly chose 124 from the 209 total lunch boxes.

The percentage of the lunch boxes which contained no vegetables was 10 .

Table 4. Relationship between the types of vegetables and the mothers' concerns for children's packed lunch

\begin{tabular}{llllllllll}
\hline The kinds of vegetables & 0 & & 1 & & 2 & & 3 & & \multirow{2}{*}{ Fisher's exact test } \\
\cline { 2 - 7 } in the lunch box & $\mathrm{N}$ & $\%$ & $\mathrm{~N}$ & $\%$ & $\mathrm{~N}$ & $\%$ & $\mathrm{~N}$ & $\%$ & \\
\hline
\end{tabular}

Guardians who think that packed lunch is well-balanced

$\begin{array}{lcccccccc}\text { Always good } & 2 & (66.7) & 0 & (0) & 1 & (33.3) & 0 & (0) \\ \text { Usually } & 2 & (5.4) & 7 & (18.9) & 15 & (40.5) & 13 & (35.1) \\ \text { No concern } & 4 & (8.2) & 18 & (36.7) & 13 & (26.5) & 14 & (28.6) \\ \text { Sometimes not good } & 1 & (7.7) & 8 & (61.5) & 3 & (23.1) & 1 & (7.7) \\ \text { Never } & 2 & (66.7) & 0 & (0) & 1 & (33.3) & 0 & (0)\end{array}$

Mothers who consider nutritional balance to be the most important thing

\begin{tabular}{lccccccccc} 
Very much & 9 & $(12.3)$ & 30 & $(41.1)$ & 21 & $(28.8)$ & 13 & $(17.8)$ & $0.021^{*}$ \\
Not at all & 4 & $(7.8)$ & 10 & $(19.6)$ & 18 & $(35.3)$ & 19 & $(37.3)$ & \\
\hline
\end{tabular}

Note. The types of vegetables were assessed using a Fisher's exact probability test; ${ }^{*} \mathrm{p}<0.05,{ }^{* *} \mathrm{p}<0.01$ 
Table 5. Relationship between the presence of tomatoes and the mothers' concerns for children's packed lunch

\begin{tabular}{|c|c|c|c|c|c|}
\hline & \multicolumn{4}{|l|}{ Tomato } & \multirow{3}{*}{$\begin{array}{l}\text { Fisher's } \\
\text { exact test }\end{array}$} \\
\hline & \multicolumn{2}{|l|}{ Presence } & \multicolumn{2}{|c|}{ Absence } & \\
\hline & $\mathrm{N}$ & $\%$ & $\mathrm{~N}$ & $\%$ & \\
\hline \multicolumn{6}{|c|}{ Mothers who consider nutritional balance to be the most important thing while preparing the packed lunch } \\
\hline Very much & 29 & $(56.9)$ & 22 & $(43.1)$ & \multirow{3}{*}{$0.027^{*}$} \\
\hline Not at all & 26 & $(35.6)$ & 47 & $(64.4)$ & \\
\hline \multicolumn{5}{|c|}{ Lunch box preparing time } & \\
\hline Over $45 \mathrm{~min}$ & 2 & $(22.2)$ & 7 & $(77.8)$ & \multirow{6}{*}{$0.013^{*}$} \\
\hline $30 \min \sim$ & 13 & (36.1) & 23 & (63.9) & \\
\hline $20 \mathrm{~min} \sim$ & 22 & $(61.1)$ & 14 & $(38.9)$ & \\
\hline $10 \mathrm{~min} \sim$ & 6 & $(37.5)$ & 10 & $(62.5)$ & \\
\hline $5 \min \sim$ & 0 & $(0)$ & 4 & (100) & \\
\hline Less than $5 \mathrm{~min}$ & 3 & $(100)$ & 0 & $(0)$ & \\
\hline
\end{tabular}

Note. Tomatoes present in the lunch box as assessed by a Fisher's exact test; ${ }^{*} \mathrm{p}<0.05$

\section{Discussion}

In this study, we aimed to investigate the percentage of space in children's lunch boxes accounted for by the vegetables and the effect of food preference and mothers' concerns on this percentage as well as the relationship between mothers' concerns for children's lunch boxes and their contents.

The percentage of 'vegetables' area in the lunch boxes was $11.9 \% \pm 7.8 \%$. The majority of children's lunchbox capacity was either $360 \mathrm{~mL}$ or $450 \mathrm{~mL}$. The percentage of 'vegetables' consumed was smaller than the increase in vegetable consumption as stipulated by Health Japan 21 (the second edition) (The Minister of Health, Labour and Welfare, 2013). This policy aims to ensure an intake of $350 \mathrm{~g}$ vegetables per day. Therefore, the percentage of vegetables in the lunches in this study was very far from the ideal proportion. More research is needed to determine the strategies for increasing this percentage.

In addition, when the percentage of the 'vegetables' area was above 11\%, a larger percentage of mothers reported a mindfulnes towards vegetables $(\mathrm{p}<0.01)$ and prepared a well-balanced packed lunch $(\mathrm{p}<0.01)$; a smaller percentage of them used frozen food, and the number of foods disliked by their children was smaller $(\mathrm{p}<0.01$; Table 2) than when the area was below $11 \%$. It has been reported that there is a strong correlation of the intake of fruits and vegetables with preferences and accessibility. The correlation observed between the children's and parents' intake of fruits and vegetables indicates that the parents' habits are a potential determinant for that of the children's (Bere \& Kleep, 2004). It has also been reported that infants who received repeated dietary exposure to a particular food tend to prefer its flavour and, even, consume it more (Forestell \& Mennella, 2007). Therefore, it is important to try to reduce the food types which children dislike during childhood by cooking well-balanced packed lunches, which includes not only fish and meat but also vegetables. By calculating the percentage of 'vegetables' area, mothers' food concerns and a balanced or unbalanced diet in children can be predicted.

When the percentage of 'vegetables' area was above $11 \%$, the amount of time the children watched TV was smaller, and the number of children who considered school lunch to be enjoyable was greaterthan when the area was below $11 \%$ ( $\mathrm{p}<0.05$ for both; Table 2). Thus, it may be an indirect relation and not a direct one. Kristiansen et al. (2013) suggested that a higher academic background of the parents was associated with a smaller amount of time spent watching TV; lower frequency of watching TV in the child's bedroom; greater amount of exercise; consumption of more fruits and vegetables, fewer sweets and less soft drinks and fast food and with more regular meals. Children's propensities to consume high-fat and high-sugar foods were positively associated with high-risk television behaviours (Lissner et al., 2012). Our previous study suggested that children's preferences were related to enjoying the school lunch (Osera et al., 2014). The percentage of 'vegetables' area may influence not only children's preferences, contents of their lunch boxes and mothers' concerns for these contents but also the amount of time spent watching TV and enjoying the school lunch. These two indirect additional items, i.e., the amount of time spent watching TV and enjoying the school lunch may be related to the children's lifestyle and preferences for particular food types. Thus, by calculating the percentage of 'vegetables' area in the lunch box, mothers' food concerns for children's packed lunch and children's preferences, as well as the amount of time the children spend watching TV and enjoying a school lunch can be predicted.

Table 3 shows that in the children's lunch box containing vegetables, half of the items were a combination of 
tomatoes and other vegetables. Almost all the children consumed one item of vegetables, and it was only a mini tomato, which is almost $10 \mathrm{~g}$. Overall, the percentage of 'vegetables' area in the lunch boxes was smaller than the recommended Japanese dietary intake. Rogers investigated the primary school children's packed lunches in the UK. The total intake of fruit and vegetables for boys and girls was found to be $53.7 \mathrm{~g}$ and $66.6 \mathrm{~g}$, respectively. Although the nutritional guidelines recommend that lunchtime meals should include one portion of both fruits and vegetables, the actual intake clearly fell far short of this, irrespective of meal type (Rogers et al., 2007).

Mothers' concerns for children's packed lunch were related to the vegetable items in the lunch boxes $(p<0.01$; Table 4). These result shows that more types of vegetables in the lunch box indicate the mother's concern to be higher. Our previous study suggested that a mother's attitude toward her child's acquisition of healthy food habits has an effective influence on children's consumption of soybean products and that a mother's positive attitude toward soybean products may be influence her children's consumption of soybean products (Osera et al., $2016 \mathrm{~b}$ ). The presence of tomatoes was related with a greater concern about the nutritional balance and a shorter cooking time (Table 5). Therefore, the presence of tomatoes in the children's lunch box may be referred a good index. Hubbard et al. (2014) suggested that those who design school wellness policies should take initiatives to work collaboratively with parents to improve the quality of foods brought from home. Moreover, Blissett (2011) suggested that the context of an authoritative parenting and feeding style is associated with better fruit and vegetable consumption during the childhood years. It is recommended that children's lunch box includes a tomato because it is easy to consume about $10 \mathrm{~g}$ of brightly coloured vegetables.

Our study is cross-sectional; thus, we could not clearly demonstrate a cause and effect relationship. Practical intervention aimed at parents must be implemented as a long-term solution (Cleghorn et al., 2009). The smart lunch box intervention, targeting both parents and children, has led to small improvements in the food and nutritional content of the children's packed lunch (Evans et al., 2010b). In order to do so, a more effective strategy that may be appropriate for use in an intervention is needed. In future, we will attempt to perform a study on how to improve the contents of children's lunch boxes. However, the findings from the present study suggest target areas for improvement of intervention strategies.

In conclusion, the percentage of consumption of vegetables in the studied Japanese children was far lower than the recommended consumption per day in Japan. The percentage of 'vegetables' area in the lunch box seems to be related to mothers' concerns for vegetables and to children's preferences. In addition, vegetable amounts in packed lunch may be related to mothers' concerns for vegetables and children's preferences.

\section{Acknowledgments}

We thank all the children, their guardians and the teachers at the kindergartens and nursery schools for their participation and cooperation with our questionnaire.

\section{References}

Apped, L. J., Moore, T. J., Obarzened, E., William, M. V., Laura, P. S., Frank. M. S., George, A. B., ... David, W. H. (1997). A clinical trial of the effects of dietary patterns on blood pressure. The New England Journal of Medicine, 336(16), 1117-1124. http://dx.doi.org/10.1056/NEJM199704173361601

Bauer, K. W., Larson, N. I., Nelson, M. C., Story, M., \& Neumark-Sztainer, D. (2008). Socio-environmental, personal and behavioral predictors of fast-food intake among adolescents. Public Health Nutrition, 12(10), 1767-1774. http://dx.doi.org/10.1017/S1368980008004394

Bere, E., \& Kleep, K. (2004). Correlates of fruit and vegetable intake among Norwegian schoolchildren: parental and self-reports. Public Health Nutrition, 7(8), 991-998. http://dx.doi.org/10.1079/PHN2004619

Birch, L. L. (1979). Preschool children's food preferences and consumption patterns. Journal of Nutrition Behavior, 11(4), 189-192. http://dx.doi.org/10.1016/S0022-3182(79)80025-4

Birch, L. L., \& Fisher, J. (1998). Development of eating behaviors among children and adolescents. Pediatrics, 101, 539-549.

Blissett, J. (2011). Relationships between parenting style, feeding style and feeding practices and fruit and vegetable consumption in early childhood. Appetite, 57, 826-831.

http://dx.doi.org/ 10.1016/j.appet.2011.05.318

Carter, P., Gray, L.J., Troughton, J., Kamlesh, K., \& Melanie, J. D. (2010). Fruit and vegetable intake and incidence of type 2 diabetes mellitus: systematic review and meta-analysis. BMJ, 341, c4229. http://dx.doi.org/10.1136/bmj.c4229 
Cashidan, E. A. (1994) A sensitive period for learning about food. Human Nature, 5, 279-291. http://dx.doi.org/10.1007/BF02692155

Cleghorn, C. L., Evans, C. E. L., Kitchen, M. S., \& Cade, J. E. (2009). Details and acceptability of a nutrition intervention program designed to improve the contents of children's packed lunches. Public Health Nutrition, 13(8), 1254-1261. http://dx.doi.org/10.1017/S1368980009991509

Cook, L., Wardle, J., \& Gibson, E. L. (2003). Relationship between parental report of food Neophobia and everyday food consumption in 2-6 year old children. Appetite. 41, 205-206.

Dovey, T. M., Staples, P. A., Gibson, E. L., \& Halford, J. C. (2008). Food neophobias and 'picky/fussy' eating in children: A review. Appetite, 50, 181-193. http://dx.doi.org/10.1016/j.appet.2007.09.009

Evans, C. E. L., Greenwood, D. C., Thomas, J. D., \& Cade, J. E. (2010a). A cross-sectional survey of children's packed lunches in the UK: food- and nutrient-based results. Journal of Epidemiology \& Community Health, 64, 977-983. http://dx.doi.org/10.1136/jech.2008.085977

Evans, C. E. L., Greenwood, D. C., Thomas, J. D., Cleghorn, C. L., Kitchen, M. S., \& Cade, J. E. (2010b). SMART lunch box intervention to improve the food and nutrient content of children's packed lunches: UK wide cluster randomised controlled trial. Journal of Epidemiology \& Community Health, 64, 970-976. http://dx.doi.org/10.1136/jech.2008.085837

Forestell, C. A., \& Mennella, J. A. (2007). Early determinants of fruit and vegetable acceptance. Pediatrics, 120, 1247-1254. http://dx.doi.org/10.1542/peds.2007-0858

Hlimi, T., Skinner, K., Hanning, R. M., Martin, I. D., \& Tsuji, L. J. (2012). Traditional food consumption behavior and concern with environmental contaminants among Cree schoolchildren of the Mushkegowuk territory. International Journal of Circumpolar Health, 71, 17344. http://dx.doi.org/10.3402/ijch.v71i0.17344

Hubbard, K., Must, A., Eliasziw, M., Folta, S., \& Goldberg, J. (2013). What elementary school children bring from Home to Eat at School. J Acad Nutr Diet, 113(9), A91.

Hubbard, K., Must, A., Eliasziw, M., Folta, S. C., \& Goldberg, J. (2014). What's in Children's Backpacks: Foods Brought from Home. Journal of the Academy of Nutrition and Diet, 114, 1421-1431. http://dx.doi.org/10.1016/j.jand.2014.05.010

Ilingworth, R. S. \& Lister, J. (1964). The critical or sensitive period, with special reference to certain feeding problems in infants and children. The Journal of Pediatrics, 65, 839-848.

http://dx.doi.org/10.1016/S0022-3476(64)80006-8

Japan Sports Council. The report of food habits of elementary school children and junior high school students. 2010. http://www.jpnsport.go.jp/anzen/anzen_school/tyosakekka/tabid/1490/Default.aspx (accessed 16 February 2016)

Kristiansen, H., Juliuson, P. B., Eide, G. E., Roelants, M., \& Bjerknes, R. (2013). TV viewing and obesity among Norwegian children: the importance of parental education. Acta Paediatrica, 102(2), 199-205. http://dx.doi.org/10.1111/apa.12066

Lissner, L., Lanfer, A., Gwozdz, W., Olafsdottir, S., Eiben, G., Moreno, L A., ... Reisch, L. (2012) Television habits in relation to overweight, diet and taste preferences in European children: the IDEFICS study. European Journal of Epidemiology, 27, 705-715. http://dx.doi.org/10.1007/s10654-012-9718-2

MacFarlane, A., Crawford, D., \& Worsley, A. (2010). Associations between parental concern for adolescent weight and the home food environment and dietary intake. Journal Nutrition Education and Behavior, 42(3), 152-160. http://dx.doi.org/10.1016/j.jneb.2008.11.004

Nicklas, T. A., Baranowski, T., Baranowski, J. C., Cullen, K., Rittenberry, L., \& Olvera, N. (2001). Family and childcare provider influences of preschool children's fruit, juice, and vegetables consumption. Nutrition Reviwew, 59(7), 224-235.

Osera, T., Tsutie, S., Kobayashi, M., \& Kurihara, N. (2012). Relationship of mother's food preferences and attitudes with children's preferences, Food Nutrition Sciences, 3, 1461-1466.

http://dx.doi.org/10.4236/fns.2012.310190

Osera, T., Tsutie, S., Kobayashi, M., \& Kurihara, N. (2014). A Retrospective Study on the Relationship of Changes in Likes/Dislikes with Food Habits in 4- and 6-Year-Old children. European Journal of Nutrition 
\& Food Safety, 4(4), 604-613.

Osera, T., Tsutie, S., Kobayashi, M., \& Kurihara, N. (2016a). Associations between Children's Food Preferences and Food Habits towards Healthy Eating in Japanese Children. Journal of Child \& Adolescent Behavior. 4(3), 1000292. http://dx.doi.org/10.4172/2375-4494.1000292

Osera, T., Tsutie, S., Kobayashi, M., \& Kurihara, N. (2016b). Using Soybean Products in School Lunch for Health Education may improve Children's Attitude and Guardians' Knowledge in Kindergarten. Journal of Child \& Adolescent Behavior, 4(5), 1000310. http://dx.doi.org/10.4172/2375-4494.1000310

Rees, G. A., Richards, C. J., \& Gregory, J. (2008). Food and nutrient intakes of primary school children: a comparison of school meals and packed lunches. Journal of Human Nutrition and Dietetics, 21, 420-427. http://dx.doi.org/10.1111/j.1365-277X.2008.00885.x

Rogers, I. S., Ness, A. R., Hebditch, K., Jones, L. R., \& Emmett, P. M. (2007). Quality of food eaten in English primary schools: school dinners vs packed lunches. European Journal of Clinical Nutrition, 61, 856-864. http://dx.doi.org/10.1038/sj.ejcn.1602592

Sanigorski, A. M., Bell, A. C., Kremer, P. J., \& Swinburn, B. A. (2005). Lunchbox contents of Australian school children: room for improvement. European Journal of Clinical Nutrition, 59, 1310-1316. http://dx.doi.org/10.1038/sj.ejcn.1602244

Smithers, G., Gregory, J., Bates, C. L., Prentice, A., Jackson, L. V., \& Wenlock, R. (2000). The National Diet and Nutrition Survey: young people aged 4-18 years. Nutrition Bulletin, 25(2), 105-111. http://dx.doi.org/10.1046/j.1467-3010.2000.00027.x

The Minister of Health, Labour and Welfare Health Japan 21 (the second term) 2013. http://www.mhlw.go.jp/seisakunitsuite/bunya/kenkou_iryou/kenkou/kenkounippon21/en/kenkounippon21 (accessed 3 April 2016)

Vereecken, C., \& Maes, L. (2010). Young children's dietary habits and associations with the mothers' nutritional knowledge and attitudes. Appetite, 54, 44-51. http://dx.doi.org/10.1016/j.appet.2009.09.005

World Cancer Research Fund \& American Institute for Cancer Research. Food, Nutrition and Physical Activity and the Prevention of Cancer: A Global Perpsective. 2007.Washington, DC: WCRF/AICR. http://www.aicr.org/assets/docs/pdf/reports/Second_Expert_Report.pdf. (accessed 16 February 2016)

Zhang, X., Shu, X. O., Xian, Y. B., Yang, G., Li, H., Gao, J., Cai, H., Gao, Y. T., \& Zheng, W. (2011). Cruciferous vegetable consumption is associated with a reduced risk of total and cardiovascular disease mortality. American Journal of Clinical Nutrition, 94, 240-242. http://dx.doi.org/10.3945/ajcn.110.009340

\section{Copyrights}

Copyright for this article is retained by the author(s), with first publication rights granted to the journal.

This is an open-access article distributed under the terms and conditions of the Creative Commons Attribution license (http://creativecommons.org/licenses/by/3.0/). 